\title{
Three-Year Follow Up of Customized Glass Fiber Esthetic Posts
}

\author{
Rogério Goulart da Costa ${ }^{a}$ \\ Eduardo Christiano Caregnatto de Morais ${ }^{b}$ \\ Moira Pedroso Leãob \\ Márcio José Fraxino Bindoc \\ Edson Alves Campos ${ }^{d}$ \\ Gisele Maria Correre
}

\section{ABSTRACT}

Customized glass fiber posts that is well adjusted into the root canal and have mechanical properties similar to those of dentin may be a suitable treatment for severely compromised endodontically treated teeth. This article reports a 3-year follow up of severely damaged endodontically treated teeth restored with unidirectional fiber glass customized post and core system instead of a conventional fiber post. The fabrication of this glass fiber customized post is a simple technique, providing an increased volume of fibers into the root canal, and an adequate polymerization of the post-core system. Over a three-year period, the treatments demonstrated good clinical and radiographic characteristics, with no fracture or loss of the post and/or crown. This technique can be considered effective, less invasive, and suitable for restore endodontically treated teeth. (Eur J Dent 2011;5:107-112)

Key words: Fiber-reinforced composite; Post and core system; Intraradicular retention; Oral rehabilitation.

1. a Professor of Dental Prosthesis of the Federal Institute for Education, Science and Technology of Paraná Department of Proshtetic Dentistry, Curitiba, PR, Brazil.

b Professor of the School of Dentistry of Positivo University, Department of Restorative Dentistry, Curitiba, PR, Brazil.

c Professor of Federal University of Paraná, Department of Restorative Dentistry, Curitiba, PR, Brazil.

d Professor of State University Paulista Julio de Mesquita Filho (UNESP). Department of

Restorative Dentistry, Araraquara, SP, Brazil.

e Professor of the Masters Program in Clinical Dentistry of Positivo University, Curitiba, PR, Brazil.

- Corresponding author:

Prof. Eduardo Christiano Caregnatto de Morais Rua Professor Pedro Viriato Parigot de Souza, 5300 CEP 81280-330, Campo Comprido,

Curitiba, Paraná Brazil.

Phone: +55 4133173403 Fax: +55 4133173082

E-mail: eduardomoraisdup.com.br

\section{INTRODUCTION}

The rehabilitation of dental structure lost by trauma or caries requires an adequate planning based on the clinical situation. The restoration of endodontically treated and severely damaged teeth has been a concern of the clinicians ${ }^{1}$ and the researchers still seek the most adequate technique and material to restore these teeth.

Several materials and techniques have been proposed to restore severely damaged endodontically treated teeth, including various post and core systems $^{2}$ that can be classified into two main types: metal posts and cores that are custom cast as a single piece, and two-element designs comprising a prefabricated post to which a composite core is subsequently adapted. ${ }^{3}$ However, no consensus existed on which technique and material is best suited for use. ${ }^{4}$ 
The use of metal posts results in a heterogeneous combination of dentin, metallic post, cement, and core materials. This situation can lead to concentration of stresses in uncontrolled areas that are vital to the root, ${ }^{5}$ causing root fractures with the time.

The restoration of damaged endodontically treated teeth with material that have physical and mechanical properties similar to those of dentin has become a major objective of dentistry. The use of materials that can bond to both dentin and core material can improve distribution of forces along the roots, contributing to the reinforcement of the tooth. ${ }^{6}$

In addition, there has been an increased demand from patients and clinicians for aesthetic treatments. Consequently, the use of metal-free crowns, as well as esthetic post and core materials is increased. ${ }^{6}$

Prefabricated glass fiber post has been widely used and show a relatively success rate because ${ }^{7}$ their properties are similar to those of dentin. ${ }^{8}$ They are esthetic, more practical, less expensive, and less invasive than metal post and core systems. ${ }^{6}$ However, prefabricated fiber posts are in general cylindrical and have a standardized diameter in accordance with the system. The manufactures recommend the use of these posts on cases where there is a sufficient coronal tooth structure remain. In addition, for stresses reduction on the root, a long and thin fiber post should be used. ${ }^{9}$

Therefore, not only the material but also the design of the post and the remaining dental structure affects the resistance of endodontically teeth restored with these systems. ${ }^{10}$ The amount of dentin to retain the core material and the nature of internal root structure are important factors for the success of the treatment.6,11 Usually, clinicians encounter severely enlarged and/or elliptical root canals, where prefabricated cylindrical posts would not be indicated. On such cases, alternative methods to prepare the post and core foundation should be selected.

The use of fiber-reinforced composites (FRC) has been proposed for the post and core system, as customized posts. ${ }^{12}$ Customized post and core system involve the use of glass fibers to fabricated posts and the use of a resin composite to construct the core over the fiber post. This system is directly luted into the root canal. ${ }^{12,13}$ This applica- tion has been used by many dentists, but there is a lack of scientific evidence supporting the use of this technique, especially regarding the longevity of such treatment.

The purpose of this report is to present a 3-year follow up of severely damaged endodontically treated teeth restored with unidirectional fiber glass customized post and core system.

\section{CASE REPORT}

The technique illustrated on these cases reported was undertaken on patients treated by the authors in a solo prosthetic practice in Curitiba, Brazil.

\section{Case 1}

A 21 year-old woman presented to the clinic with a right maxillary pre-molar with an extensive coronal loss. The patient selected an indirect composite restoration (Targis/Vectris, Ivoclar Vivadent - Principality of Liechtenstein) because of its esthetic advantage. For the rehabilitation, a customized fiber glass dowel was selected due to the enlarged and fragile internal root anatomy and the remaining coronal dentin, showing an adequate endondontic treatment, with no periapical lesion. The canal was prepared and an impression with condensed silicon (Speedex, Vigodent - RJ Brazil) was taken for both arches. The molds were cast with type $V$ gypsum (Extradur, Polidental - SP - São Paulol and sent to the laboratory.

For the dowel and core preparation, the following indirect fabrication technique was undertaken. A model separator of the prepared dowel space was applied on the working cast using a photocured composite resin model separator (Kota - SP - Brazil); a sheaf of glass fibers, impregnated with a proper monomer, with proper length and diameter (Vectris Pontic, Ivoclar Vivadent) was prepared (Figure 1A); the fiber was packed into the prepared dowel space with a handheld instrument, ensuring that the fiber reached the bottom, modeling the internal radicular anatomy until the total filling of the dowel space (Figure 1B). Then, the fibers were polymerized with a light-polymerizing apparatus (30 s each fiber increment); the fiber post was carefully removed from the cast, the whole fiber dowel was polymerized and placed back onto the cast; the excess part of the fiber was cut with a diamond disk. 
To prepare the core a laboratory composite Targis/Vectris was added to the dowel to create an appropriated form of the core (Figure 2A). The dowel and core system was polymerized using a light unit (Quick, Ivoclar Vivadent), and a furnace (Lumamat 100, Ivoclar Vivadent), to complete the foundation. The dowel and core system was finished with diamond bur and $50 \mu \mathrm{m}$ aluminum oxide powder (Figure 2B).

Then, the customized dowel was cemented to the root using a resin cement (Rely X Arc, 3M/ ESPE, Saint Paul - USA), following manufacturer's instructions (Figure 3). An indirect composite crown (Targis/Vectris) was also cemented using the same resin cement.

\section{Case 2}

A 36 year-old woman presented to the clinic with a right maxillary pre-molar needing prosthetic rehabilitation with intraradicular retention. The same prosthetic treatment described above was selected for this case.

\section{Case 3}

A 48 year-old man presented to the clinic needing prosthetic rehabilitation on the anterior maxil-

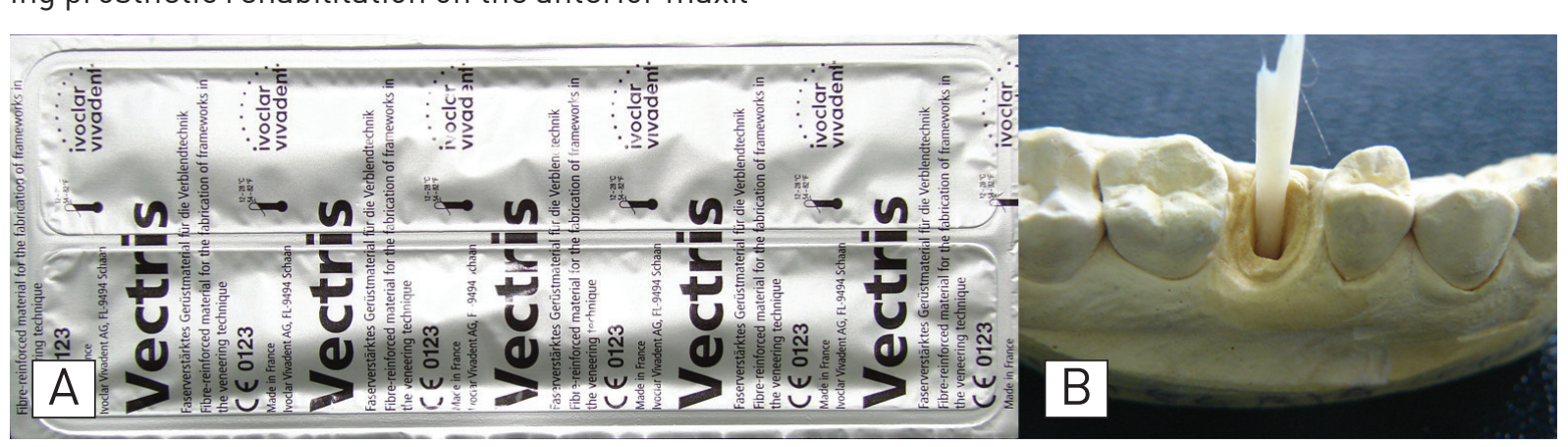

Figure 1. Pre-impregnated glass fiber (A) and packing the fibers into the dowel space on the working cast (B).

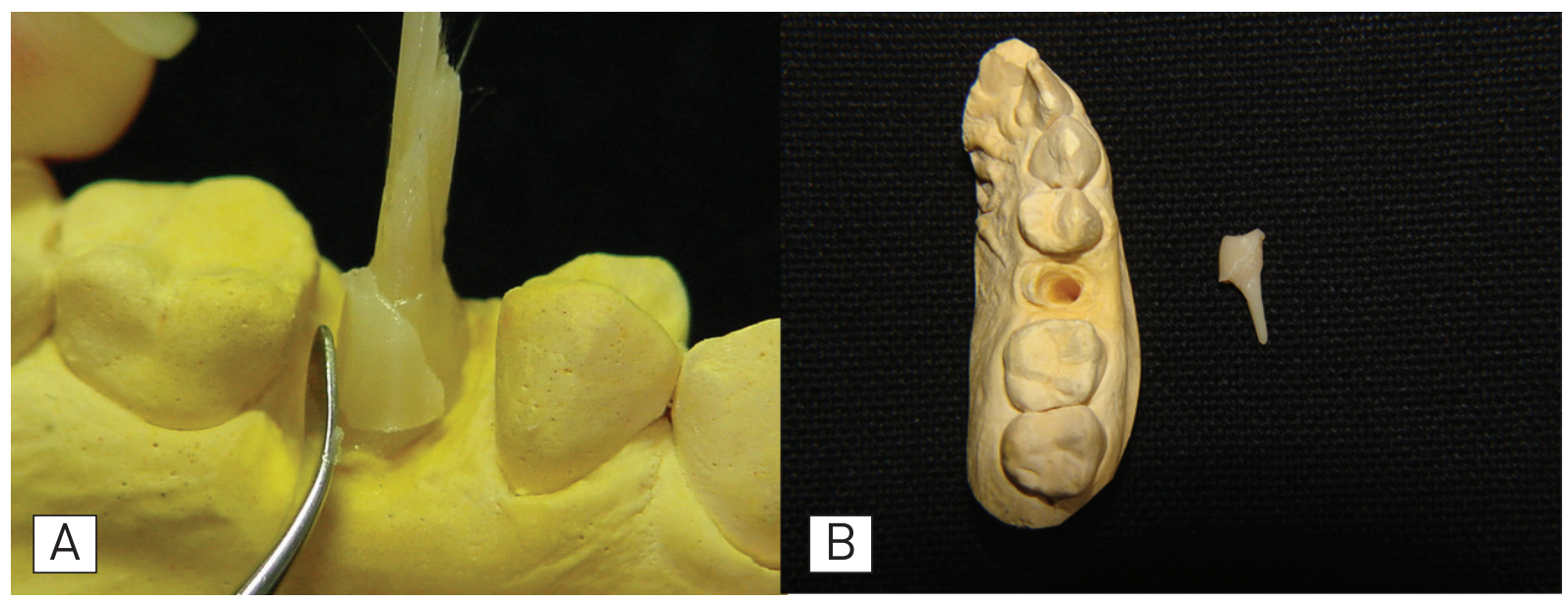

Figure 2. Preparation of the composite resin core (A). Customized dowel-core system (B). lary teeth, from right lateral incisor to left canine. The treatment option selected was lithium disilicate glass metal free crowns. In order to obtain a better esthetic result, and because of the internal root anatomy, customized fiber dowels were also selected however, only on left maxillary central incisor a metallic dowel and core system was maintained and a superstructure was prepared to improve the esthetic result, masking the metal opacity.

The patients were clinically and radiographically evaluated after 3 years of the treatment (Figures 4, 5 and 6). During this period, it was evaluated clinically the retention of the customized dowel and crown and if it was capable to resist the masticatory forces without fracture or dislodgement of the root. Regarding the radiographic analysis, it was observed the cervical adaptation of the crown, presence of fractures of the dowel-core system and integrity of the cement line. All teeth showed adequate clinic and radiographic characteristics, without fractures or dislodgement of the dowelcore system or the crown. 


\section{DISCUSSION}

The chewing forces in adults vary from 7 to 15 $\mathrm{kgf}$ and the maximum biting force can be up to 90 Kgf. ${ }^{14}$ To achieve a clinical success, the restored tooth should be resistant to these forces over time. Therefore, the post-core system should present

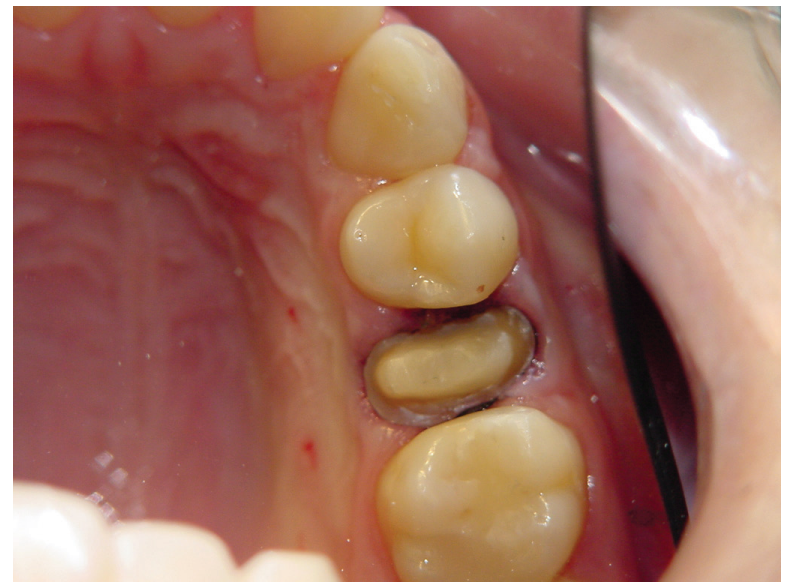

Figure 3. Customized dowel luted prior to crown cementation.



Figure 4. Radiographic image of case 1 after 3 years. similar properties to those of dentin, and an adequate stress distribution along the root. When the fiber post with a similar modulus of elasticity to that of intraradicular dentin is used for restoration, less stress is transferred from the post to the dentin. ${ }^{15}$

Fiber-reinforced composite posts are reported to have similar modulus of elasticity to dentin. ${ }^{4,8}$ It is believed that the creation of a mono-block dentin-post-core system through the dentinal bonding would allow better stress distribution of forces along the root. ${ }^{1}$

In this study the post and core system was customized using glass fibers originally designed for tooth-colored restorations and fixed partial dentures (Vectris Pontic). This material is composed of unidirectional R-glass ( $65 \%$ weight), a Bis-GMA/ UDMA/DDMA/TEGDMA matrix, and SiO2 filler particles (3.5\% weight). According to Dyer et al, ${ }^{16}$ the

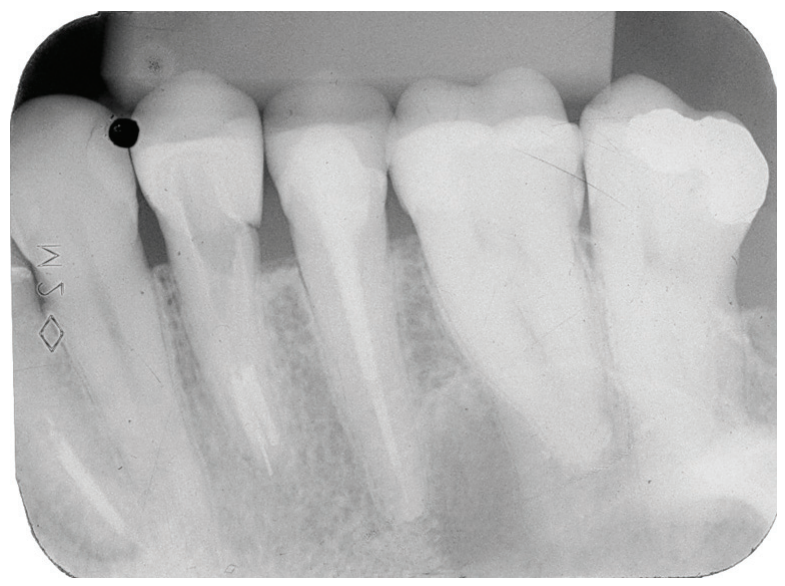

Figure 5. Radiographic image of case 2 after 3 years.

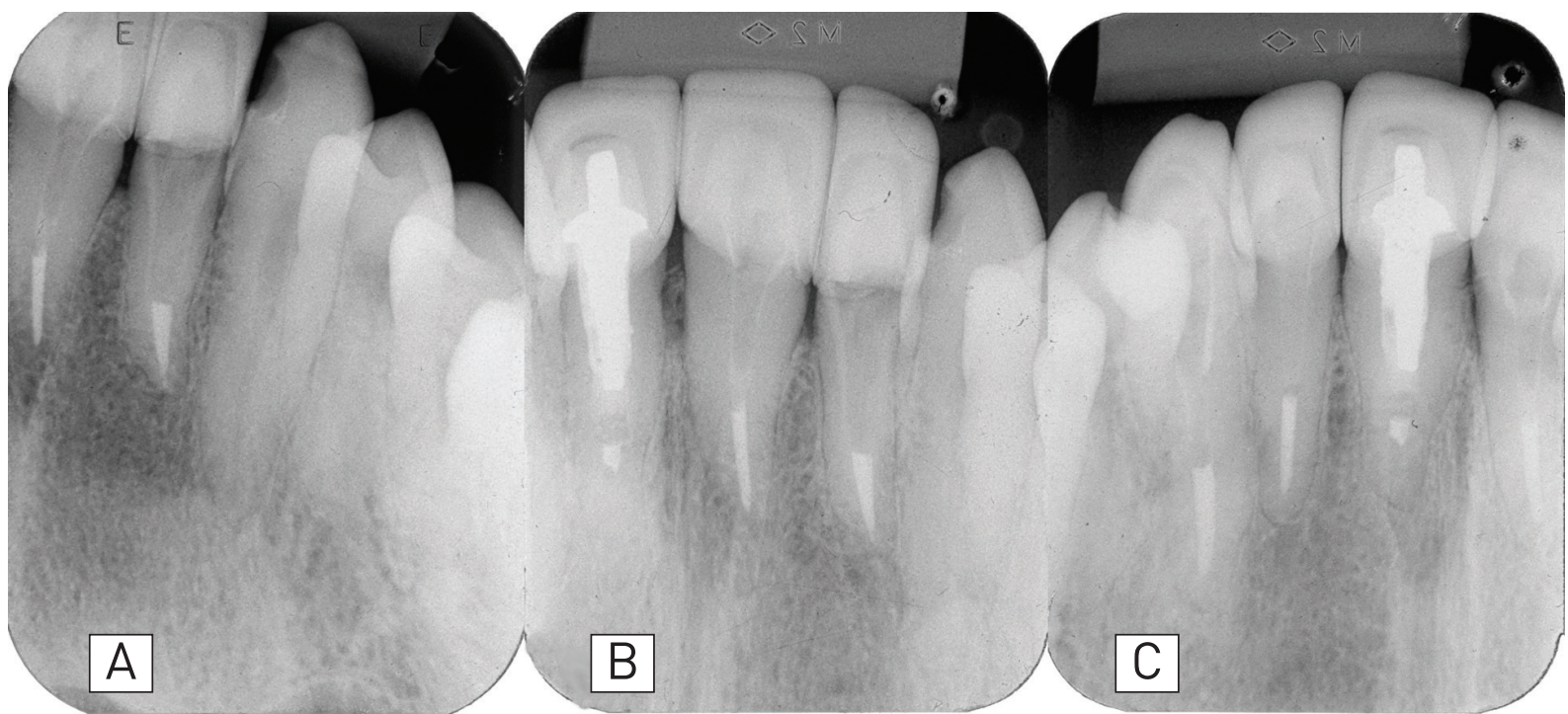

Figure 6. Radiographic image of case 3 after 3 years. Right maxillary lateral incisor (A), right central incisor and left central incisor - note the metal core dowel (B), left ateral incisor and left canine (C).

European Journal of Dentistry 
positioning and direction of different type of fibers can influence the fracture load of FRC. They showed that unidirectional glass fiber appears to reinforce the test specimen, increasing its flexural rigidity, and consequently its load of failure.

Customization of the intraradicular retention produces a better adaptation within the dentin/cement/post interface, since during the fabrication process the glass fibers will be adjusted into the root canal, copying its anatomy. The glass fibers can be easily prepared to a thick layer and fill the post space as densely as possible, reducing the cement layer. The technique is simple and requires the conventional indirect fabrication tools. The customized post can be sufficiently polymerized according to manufacturer's instructions. ${ }^{9}$

The customized post will be fixed into the canal with a thin layer of the resin cement, instead of different amounts of cement present on regular fiber glass post fixation. A large cement line between the prefabricated post and the canal wall could cause of displacement of post. ${ }^{17,18}$ Also, thicker layers of the luting material will produce more shrinkage strain, probably creating more stress during polymerization and reducing bond strength, as demonstrated by Kremeier et al. ${ }^{19}$

Customized posts can be affected by the volume of core, the dentin bonding area on the coronal portion of the posts, and the size of the canal. The strength of the customized post is directly proportional to the amount of fiber and composite at the coronal portion of the posts. ${ }^{6}$ On widened post-spare preparations in severely compromised roots, a customized post may present a better clinical result, mainly because flared canals allow the placement of more fiber and more composite compared with the narrow canals as demonstrated by Newman et al. ${ }^{6}$ Also, on these cases, the cross-sectional area at the post-core junction will be increased what may lead to increased strength of the post-core systems. ${ }^{1}$ In this study both patients presented widened root canal preparations, indicating the use of customized post in order to provide an effective and minimally invasive foundation, and to achieve a better clinical result.

The proposed treatment (customized glass fiber posts) showed good clinical results on the cases reported. After 3 years, good coronal seal were achieved with the indirect crowns and customized glass fiber posts. It was observed in all cases adequate clinic and radiographic characteristics of the crown-post system. Except for the radiographic images of cases 2 and 3 that suggest a lack of adaptation of the crowns; however, the clinical inspection using 5 probe does not reveal any problem regarding the crowns adaptation. A possible explanation for this is that the space, observed radiographically, was filled with the resin cement (Rely X Arc, 3M/ESPE) that does not have radiopacity.

The use of indirect resin composite crown (case 1 and 2) was the selected option because it is more economical from the patient's point of view, compared with other indirect restorations (ceramic). In addition, full ceramic restorations would be more susceptible to brittle failure; while ductile materials utilized their plasticity to reduce stress concentration along the crack tip. ${ }^{20}$

Regarding the failure occurrence on fiberreinforced composite and glass fiber customized posts, studies show that the majority of the failures occur on the cervical portion of the root including the core-dentin interface because the stresses were concentrated in the cervical area and the outer root surface. This type of fracture is amenable to repair. Therefore, customized posts have another advantage that is the ability to be refurbished with the potential to save tooth structure and increase the longevity of restorations at a lower cost. ${ }^{21}$

\section{CONCLUSIONS}

The use of unidirectional glass fibers customized post, modeling the internal anatomy of the root canal, reported on these cases showed adequate clinical and radiographic characteristics after 3 years. This technique can be considered effective, less invasive, and suitable for restore endodontically treated teeth.

\section{REFERENCES}

1. Sirimai S, Riis DN, Morgano SM. An in vitro study of the fracture resistance and the incidence of vertical root fracture of pulpless teeth restored with six post-and-core systems. J Prosth Dent 1999;81:262-269.

2. Bonfante G, Kaizer OB, Pegoraro LF, do Valle AL. Fracture strength of teeth with flared root canals restored with glass fibre posts. Int Dent J 2007;57:153-160. 
3. Martinez-Insua A, Da Silva L, Rilo B, Santana U. Comparison of the fracture resistances of pulpless teeth restored with a cast post and core or carbon-fiber post with a composite core. J Prosth Dent 1998;80:527-532.

4. Akkayan B, Gulmez T. Resistance to fracture of endodontically treated teeth restored with different post systems. $J$ Prosth Dent 2002;87:431-437.

5. Fredriksson M, Astback J, Pamenius M, Arvidson K. A retrospective study of 236 patients with teeth restored by carbon fiber-reinforced epoxy resin posts. J Prosth Dent 1998;80:151-157.

6. Newman MP, Yaman P, Dennison J, Rafter M, Billy E. Fracture resistance of endodontically treated teeth restored with composite posts. J Prosth Dent 2003;89:360-367.

7. Qing H, Zhu Z, Chao Y, Zhang W. In vitro evaluation of the fracture resistance of anterior endodontically treated teeth restored with glass fiber and zircon posts. J Prosth Dent 2007;97:93-98.

8. Qualtrough AJ, Mannocci F. Tooth-colored post systems: a review. Oper Dent 2003;28:86-91.

9. Tanoue N, Nagano K, Shiono H, Matsumura H. Application of a pre-impregnated fiber-reinforced composite in the fabrication of an indirect dowel-core. J Oral Sci 2007;49:179-182.

10. Akkayan B, Caniklioglu B. Resistance to fracture of crowned teeth restored with different post systems. Eur $J$ Prosthodont Rest Dent 1998;6:13-18.

11. Christensen G. Posts and cores: state of the art. J Am Dent Assoc 1998; 129:96-97

12. Kimmel S. Restoration and reinforcement of endodontically treated teeth with a polyethylene ribbond and prefabricated fiberglass post. Gen Dent 2000;48:700-706

13. Hornbrook DS, Hastings JH. Use of bondable reinforcement fiber for post and core build-up in an endodontically treated tooth: maximizing strength and aesthetics. Pract Periodontics Aesthet Dent 1995;7:33-42.

14. Salameh Z, Sorrentino R, Ounsi HF, Goracci C, Tashkandi E, Tay FR, Ferrari M. Effect of different all-ceramic crown system on fracture resistance and failure pattern of endodontically treated maxillary premolars restored with and without glass fiber posts. J End 2007;33:848-851.

15. Pierrisnard L, Bohin F, Renault P, Barquins M. Cornoradicular reconstruction of pulpless teeth: a mechanical study using finite element analysis. J Prosth Dent 2002;88:442448.

16. Dyer SR, Lassila LVJ, Jokinen M, Vallittu PK. Effect of fiber position and orientation on fracture load of fiber-reinforced composite. Dent Mater 2004;20:947-955.
17. Fraga RC, Chaves BT, Mello GSB, Jr JFS. Fracture resistance of endodontically treated roots after restoration. $J$ Oral Rehabil 1998;25:809-813.

18. Hunter AJ, Flood AM. The restoration of endodontically treated teeth. Part 3 Cores. Aust Dent J 1989;34:115-121.

19. Kremeier K, Fasen L, Klaiber B, Hofmann N. Influence of endodontic post type (glass fiber, quartz fiber or gold) and luting material on push-out bond strength to dentin in vitro. Dent Mater 2007;24:660-666.

20. Derand P, Vereby P. Wear of low-fusing dental porcelains. J Dent 1999;81:460-463

21. Grandini S, Goracci C, Tay FR, Grandini R, Ferrari M. Clinical evaluation of the use of fiber posts and direct resin restorations for endodontically treated teeth. Int J Prosthodont 2005;18:399-404 